\title{
PRODUCING RELEVANT MEDICAL EDUCATION THROUGH COMMUNITY-ENGAGED SCHOLARSHIP
}

\author{
Nelson Masanche Nkhoma ${ }^{1}$ \\ University of the Western Cape, South Africa
}

\begin{abstract}
Some African higher education institutions (HEIs) were founded on the notion that they would serve the specific needs of African communities. Other HEIs have borrowed the concept of community-engaged scholarship (CES) from the USA as a strategy for achieving relevance. Nonetheless, African HEIs continue to be criticized as imitators of Western universities. Drawing on Bhabha's $(1985,1994)$ concepts of "hybridity" and "resistance", this paper explores Malawian faculty members' perspectives on how they use CES as a strategy to make medical higher education relevant to their academic work. This study draws from postcolonial theory to show that faculty use CES to interpret truth claims around medical knowledge production and comply with the demands of a relevant and engaged university. The study also shows the complexities and paradoxes characterizing the ways in which academics strive to include subjugated knowledge or forge collaborations in higher education in order to promote multi-perspective. CES is oftentimes conceptualized as a hybridization of perspectives that are themselves caught up in crossfire of resistance. My research on CES noted that it is an important motivation to improving the relevance of higher education in Malawi in general and medical education in particular by bringing together the so-called 'traditional knowledge' and 'biomedicine', as well as interdisciplinary perspectives and knowledge from multiple actors. These were muddled intersections, which suggest a uniquely Sub-Saharan African (SSA) approach to CES and relevant medical education for Malawi. Therefore, the paper argues that faculty members resist the simplistic critique of their work as imitations of Western medical knowledge production as they perceive themselves as providing very complex and different ways of knowing in the field of medical education. Drawing from these faculty perspectives, the paper then concludes with two strategies that can enhance CES.
\end{abstract}

Keywords: Africa, Malawi, higher education, knowledge production, medical education, community engagement, hybridity.

${ }^{1}$ Correspondence: Robert Sobukwe, Road., P. Bag x 17 Bellvile 7535, Cape Town, South Africa; Email:

nnkhoma@uwc.ac.za 


\section{Introduction}

Sub-Saharan Africa's (SSA) higher education is rife with contestations over the relevance of higher education across nations and academic disciplines (Clark, 1998). Universities, international development agencies, and other related entities use the concept of $\mathrm{CES}^{2}$ to produce knowledge that is relevant to the SSA higher education sectors and local contexts (Preece, Ntseane, Modise \& Osborne, 2012; Obamba, 2013). An etic definition of CES describes it as creative intellectual work that is conducted in the context of public settings and academic interests, and to establish relationships, as well as facilitate social learning and the production of knowledge, theory, technologies and other products that advance both public and academic interests in an effort to alleviate societal problems (Furco, 2010). However, an emic view and perspectives from Malawian universities missions and faculty members, define CES as professional work relating to teaching, research, outreach, service and consultancies that enables professional growth, income generation and solves public problems. The idea of a mutual relationship with communities via teaching, research, outreach, service and consultancy is central in medical education CES.

However, the achievement of relevant medical education in SSA brings to the fore the legacies of colonial efforts that sought to shape and control people's behavior around public health and culture (Thomas, 1998). This complex higher education history gets entangled in current local contradictions and neoliberal policies on funding of higher education that emphasize monetary values other than knowledge for its own sake (Zeelen \& van der Linden, 2009). Obamba (2013) notes that contradictions arise from an enormous dependence on international partnerships for knowledge production as opposed to generating home grown collaboration to solve problems, thus warranting the view that CES in SSA imitate models from Western universities (Mamdani, 2008a; Singh, 2001; Gibbons, 1998; Eisemon, \& Balkom, 1988). Postcolonial conceptualizations in the social and historical studies of medicine and education have adopted pluralism as a nuanced and useful conceptual tool, as opposed to the distinct biomedicine or tradition, in framing medical knowledge (Pigg, 1995). Nonetheless, there exists a gap in the literature on comparative education as these postcolonial ideas do not explain how faculty members in the SSA create and practice a pluralistic and unique medical education in and through CES.

This paper examines the experiences and perceptions regarding the use of CES at a public College of Medicine (COM) in Malawi. The rationale for choosing this site is that the $\mathrm{COM}$ is a relatively new institution that is situated in an interesting post-colonial context. Malawi is a former British colony and a current vibrant partner of international universities and donors. This is a rich setting to examine the contextualization of CES and the provision of relevant medical education - a vision that COM aspires for while the institution and its faculty grapple with finding a footing in the nexus of the local and international spheres of medical education. The following section outlines the mandate of SSA universities in order to contextualize the setting. This is followed by the conceptual framework, which draws on postcolonial theory notions on "hybridity," and "resistance" in knowledge production.

The paper then describes the research setting and methods in this particular studya one year exploratory study undertaken on five faculty members at COM in Malawi. The next section explores motivations for CES in medical education and the hybridization of scientific and traditional medical knowledge, interdisciplinary collaboration, as well as the linking of actors in the health sector and tapping into the local communities. All these emerged as important aspects of CES though ridden with their own difficulties and resistance.

\footnotetext{
${ }^{2}$ See College of Medicine (COM) profile at http://www.medcol.mw/com-profile/.
} 
The faculty dealt with these complexities and resistance in CES in a unique way and this necessitated the need to conclude the paper with a discussion on the strategies that can make CES a useful tool for the establishment of context specific higher education setting.

\section{CES and its Relevance to Universities in SSA}

Scholars have long called for context specific, relevant and differentiated higher education in SSA (Altbach, 2013; World Bank, 2009; Zeelen, \& van der Linden, 2009). This takes the form of creating mutual links with various communities inside and outside the universities in order to access and share resources and knowledge (Sawyer, 2004; Clark, 1998). CES is evident in various interpretations of strategies that universities use to contribute to the social, economic, and political development of nations (Preece, 2013). Concomitantly, there are various elucidations of what is meant by relevant universities in the SSA context. The first interpretation focuses on the need for universities to engage with communities through the production of human resources, such as doctors and teachers, for the civil service and public professions (Bloom, Canning and Chan, 2006). This interpretation can be described as professional CES (Burawoy, 2010; O’Meara, 2008). Second, universities are seen as sources of expert knowledge that can drive social and economic progress (Zeleza, 2002). This interpretation considers universities as service providers that can help with good governance and offer expertise on various issues (Preece, Ntseane \& MmaB, 2012).

This can be described as public and policy CES (Preece, 2013; Burawoy, 2010). The idea of public and policy CES denotes the role institutions, such as universities, in the provision of services, which include the crafting and shaping relevant public health policies, for the public. The third form considers community engagement as the engine of development (Mamdani, 2008b; World Bank, 2007; Clark, 1998). This interpretation views universities as taking the front role in science-led development by generating knowledge via research in partnership with communities to enhance participation in the global knowledge economy (World Bank, 2007; Castells, 2010). The emphasis here is on the collaboration between universities and communities in science and technological innovation such as the improvement of biomedical technology. This can be described as innovational CES (Cloete, Bailey, Pillay, Bunting \& Maassen, 2015). The fourth conceptualization of relevant CES maps universities serving as social and cultural critics of institutions and societies (Altbach, 2013, Hale, 2008). This form, which is critical CES (Dempsey, 2010; Hale 2008), perceives a university as the defender of human rights and a model of democracy.

Despite these laudable goals, there are various challenges that are faced by CES and attempts at fostering relevant medical education. Some of these challenges include: limited funding for research and knowledge production; autocratic administration systems; poor reward systems for promotion; and heavy teaching loads of students (Teferra, \& Altbach, 2004; Waghid, 2002). Other scholars show that poor internet, laboratories and other material infrastructure; a shortage of human resources; interference by international actors and governments (Samoff, 1999); and community suspicions (Lazarus, Erasmus, Hendricks, Nduna, \& Slamat, 2008) impact negatively on the proliferation of CES across Africa. All these challenges apply, albeit in different ways, in the case of CES in medical education in SSA. According to Wendland (2012), the challenges for Malawi are that scientific ideas circulate and change fast; there are clinical tourists moving mostly from outside to Malawi but not the reverse; and that medical technologies circulate slowly, erratically, and sometimes not at all. These conditions enable the practice, production and intersection of multiple perspectives of CES and the production of relevant medical knowledge that is unique to SSA. The following 
section presents postcolonial theoretical concepts to critically analyze the practice of CES in SSA and Malawi.

\section{Hybridity in and Resistance to CES}

This study draws from postcolonial scholars (Appiah, 1991; Spivak and Harasym 1990). I specifically employ Bhabha's (1994) implication and interpretations of hybridity and resistance in order to explain how CES is used to attain relevant knowledge in African HEIs. Loomba (2015) suggested that there are multiple and divergent ways of applying the notion of hybridity. In this paper, I employ the concept to demonstrate the quest to cross between the scientific and traditional knowledge of healing. Moreover, in a postcolonial theoretical sense, I employ hybridity to evoke the ways in which the artificial knowledge boundaries are legitimized, challenged and resisted, in order to demonstrate the positive and negative implication of such divides and reifications. According to Bhabha (1994), hybridity helps us to see the not so easy divisions in what we consider as differences. For this paper, I consider difference in the categorizations of types of knowledge by academic disciplines, as well as actors that emanate from the local and international communities and universities enabled by CES. Bhabha (1985) postulates that contexts that articulate differences are always sights for resistance. He suggests that "resistance is not necessarily an oppositional act of political intention, nor is it the simple negation or the exclusion of the 'content' of another culture," it is rather, "the effect of an ambivalence produced within the rules of recognition of dominating discourses as they articulate the signs of cultural difference" (Bhabha, 1985: 153).

Thus, the concept of resistance helps to expose how faculty members' practices in CES within institutions that are vestiges of colonial influence directly or indirectly employ resistance, and how they themselves are being resisted in the power, knowledge, hybridization, and differentiation nexus. Hybridity and resistance oblige us to see beyond binaries and imitations in CES and to understand how multiple relationships and perspectives are (re)produced. In addition, a postcolonial critique destabilizes the simple polarization of CES in medical education where Western medical practices are the "original" and SSA medical practices a "copy." Postcolonial frameworks also provide academic tools that enable us to examine the complexities and nuances within people, communities, and institutions. The following section, therefore, explores the methods and study setting used to explore the complexities of CES in the production of relevant medical education.

\section{Exploring the Methods and Study Setting}

The research project on which data for this paper is drawn investigated the factors that drive faculty members in Malawi public universities to perform CES. The study covered three public universities with a population of 115 faculty members in the years 2014 and 2015 . The article focuses on a group of five faculty from the medical school. These faculty members were purposefully selected on the basis of CES records in the Dean of Research and Community-engagement office at the COM. The criterion and rationale for selection was twofold. First, the faculty members were selected because their work involved direct engagement with students in local or international communities via outreach, research, service, and consultancy. This drew on the evidence about their scholarly records of CES provided by the administration. The second rationale was that faculty members came from different departments and fields of specialization in order to gain multiple perspectives. Seven faculty members were selected but only five participated in the study because the other two 
were on study leave ${ }^{3}$. While the study did not primarily investigate the development and history of medical education, this paper pays particular attention to how faculty members at a medical school use community engagement to bridge scientific and traditional medical knowledge. This strategy became a prominent motivation driving faculty members' CES, hence, warranting a detailed and further analysis.

A grounded theory, as advanced by Riesman (2008), was used to identify themes and codes from the interview data. This means that I reviewed the data for repeated ideas such as professional interests, integration of knowledge and complications in CES. I grouped these into concepts such as 'motivations', 'opportunities' and 'challenges' in CES. As I re-reviewed these codes, I discovered that they resonate well with postcolonial theory concepts, such as hybridity and resistance. Rather than creating a new theory - a traditional grounded theory approach- I chose the existing postcolonial concepts to explain the contextualization of CES in a unique setting.

The interviews with faculty members explored their motivation for conducting CES using a life story approach that is also known as a narrative (Riessman, 2008; Artinson, 1998; Personal Narrative Group, 1989). A narrative is defined as events perceived by the speaker as important due to their selection, connection, evaluation and organization to tell a particular story. As a result, I asked faculty members about the origins and development of their work and career. I also asked about what drove them to conduct CES, and the kinds of barriers they faced in their work. Faculty members were also invited to tell their growing-up stories and the kind of experiences within their community that led them to decide on going to college, take up the field of study and research, and scholarly work they were performing. In addition, the interviews focused on how the faculty members ended up teaching and working at the university, and particularly, what motivated them to take up CES. Forester's (2007) ideas assisted in the analysis of the transcripts of faculty members' interviews and these were edited into faculty participants' profiles which are also called practitioner profiles. The practitioner profiles are presented in the form of a rich, thick narrative of a life story that does not include all research questions.

Riessman's (2008) approach to narratives was helpful in showing the central place of a narrative when personal health and social issues, workplaces issues, governments and institutions intersect with each other from oral sources into text and what he calls "ruling regimes" (p.3). This acted as a significant reminder, during analysis that, transforming a lived experience into language and constructing a story about it is not straightforward but invariably mediated and regulated by controlling vocabularies and power (Foucault, 1983). Narratives ${ }^{4}$ are composed and used in research, in various ways such as bringing the voice of the study participants considered marginalized or bringing to the fore a biographical background of the researcher. The current study used narratives to facilitate an understanding of how Malawian faculty members at the medical college reflect on the use of African and Western medical epistemologies through CES. This enabled the highlighting of postcolonial insights on how regimes of knowledge create hybridity and resistance to the critique that perceives African faculty as mere imitators of their Western counterparts.

The postcolonial medical education in Malawi has been affected by decimal capacity and deeply embedded polarities-traditional versus modern, indigenous healing versus

\footnotetext{
${ }^{3}$ All names of participants used for reference here are pseudo names to ensure anonymity.

${ }^{4}$ He shows that speakers connect events from oral storytelling into a sequence that is consequential for action and the meaning that the speaker wants listeners to take away from the story. Narratives can therefore be seen here as events perceived by the speaker as important due to their selection, connection, evaluation and organization to tell a particular story.
} 
biomedicine (Lwanda 2002, Mkandawire, 1998). The limited medical training and medical knowledge polarities raise the complexities of conducting CES and questions of the relevance of medical education (Broadhead \& Muula, 2002; Dahlenburg, 1993). Harries, Kumwenda, Zijlstra, Broadhead, Squire, \& Salaniponi (2003) also expose historically embedded polarities in Malawi, over the traditional versus modern and indigenous healing versus biomedicine in medical education. The traditionalists approach medical education from a functionalist perspective. Yet, for the most part, scholars in the Malawian medical education sector focused on the so-called true scientific base of medical knowledge, which often represents Western, influenced biomedical knowledge. There, however, are those who approach medical education from a problem-based perspective, where scholars are expected to discover and develop a portfolio of medical knowledge. This reality means that the focus on community service compelled medical educators at the COM to take a middle line approach by integrating the best aspects of the traditional and modern approaches and knowledge (College of Medicine, 2010). This philosophy represents the importance of service and CES in community health (Broadhead \& Muula, 2002). It also shows a clear understanding of the complexity of relevant medical education by paying attention to the local context.

Auspiciously, two decades since the establishment of the COM, there is evidence that significant strides have been made to render medical education relevant to the needs of Malawian societies, primarily through $\mathrm{CES}^{5}$. The following sections provide evidence that shows the ways in which faculty reject the narrow conceptualization of their work as mere imitation of Western medical education. Faculty members at the COM use CES to problematize false dualities in medical knowledge production by paying attention to multiple medical epistemologies, working across disciplines, and collaborating with multiple actors. Thus, the faculty actions create multiple hybridizations that constitute relevant medical education for communities, students and faculty members themselves amidst numerous challenges.

\section{Findings \\ Motivation, hybridity and resistance in CES}

The process of qualitative data analysis identified various themes. The most prominent theme here was that of making medical education relevant to the needs of communities via CES. The other sub themes were the opportunities and challenges of engaging with communities in the process of making medical education relevant. The themes resonate with Matthew's (2010) observation that the SSA faculty members stipulate their motivations for CES as enhancing the relevance of teaching, research and service, yet this work tends to be embroidered with opportunities and challenges. These themes of opportunities and challenges were understood in the postcolonial sense as a multifarious of hybridity and resistance in CES (Loomba, 2015). Building on Holland's (2009) studies in Malawi HEIs, albeit in the social sciences and humanities, these finding explore the multidimensions of CES practices in a medical school setting in order to explicate the complicated and unique forms of CES conducted by the faculty in one medical education college. Table 1

\footnotetext{
${ }^{5}$ For more information on the specific program and medical education structure at the college see a paper by Adamson S. Muula Croat Med J. Apr 2010; 51(2): 171-172. Here he also outlines that stakeholders in Malawi were not interested in providing medical education because they depended on foreign doctors present in Malawi. He notes further that, while others were skeptical about the medical college and viewed it as an ivory tower, stakeholders made several strides to make the medical school relevant to educational and health needs of the people.
} 
below shows that faculty were driven to conduct CES to contribute to their professional development, medical service provision and improve the research profile of COM.

\section{Table 1. Motivations for CES.}

\begin{tabular}{|c|c|}
\hline Faculty profile & Motivations for CES \\
\hline Dr. Dube: & As for the research and my community engagements, I was \\
\hline Assistant Professor & motivated to take it up because no one in Malawi was working \\
\hline Physiology & $\begin{array}{l}\text { in this field so there is lack of personnel especially in fertility } \\
\text { issues. That was the motivating factor. So we involve } \\
\text { communities and do both lab-based as well as community- } \\
\text { based research because we have a research resource in the } \\
\text { community as far as issues of fertility are concerned. }\end{array}$ \\
\hline
\end{tabular}

Dr. Mwala: $\quad$ My core interests are in child growth and development.[...] Senior Lecturer Right now I am focusing on very basic issues like patterns of Public Health growth in children. The health of child is directly linked to future generations and the social economic wellbeing of a community. My interest is to see progressive improvements in child health while I develop professionally.

Dr Madzi Community engaged scholarship is important to help Senior Lecturer students learn the real issues affecting health and diseases. Public Health $\quad$...we become batter teachers and better service providers by working with communities.

Dr. Nyanja:

Assistant

The motivation for doing community engagement is the Professor Chemistry background. Our work is basically a science. Science must have application to the community and public...People are influenced by money yes, but usually, it is the professional development and contribution to the community that is important.

Dr. Dziko:

I am driven to CES because of the profession. I am promoted

Lecturer

Orthopedics through research but I can also bring my knowledge to change the lives I touch. Our role at COM is to teach, research and do consultancies.

\section{Hybridity in CES}

Forester (2008) states that the use of profiles in qualitative research reveals various informative aspects about the research participants' lives and professions. The profiles of the five faculty who were part of this study at the selected COM offered rich narratives and stories that revealed their professional motivations for conducting CES, complex integration of knowledge, collaborations with numerous actors and the intersecting disciplines, which highlighted a Malawian context specific medical education. The quest for a deeper and nuanced postcolonial-based understanding of the way faculty at the medical school demonstrate hybridity in CES demanded a tabulation of the themes from the interviews in the form of a table in order to clearly juxtapose the perspectives across all five faculty members. The themes are tabulated in the table below. The presentation of all faculty 
members' entire transcript, which would have enabled an even a thicker profile, was affected by the limitation of space and associated drawbacks to constructing a long profile and narrative. The short but thick description of faculty motivations, perspective on CES and the challenges they face offered a unique way to amplify the stories and learn in detail from the faculty's professional experiences with CES as the table below shows.

Table 2. Hybridity in CES.

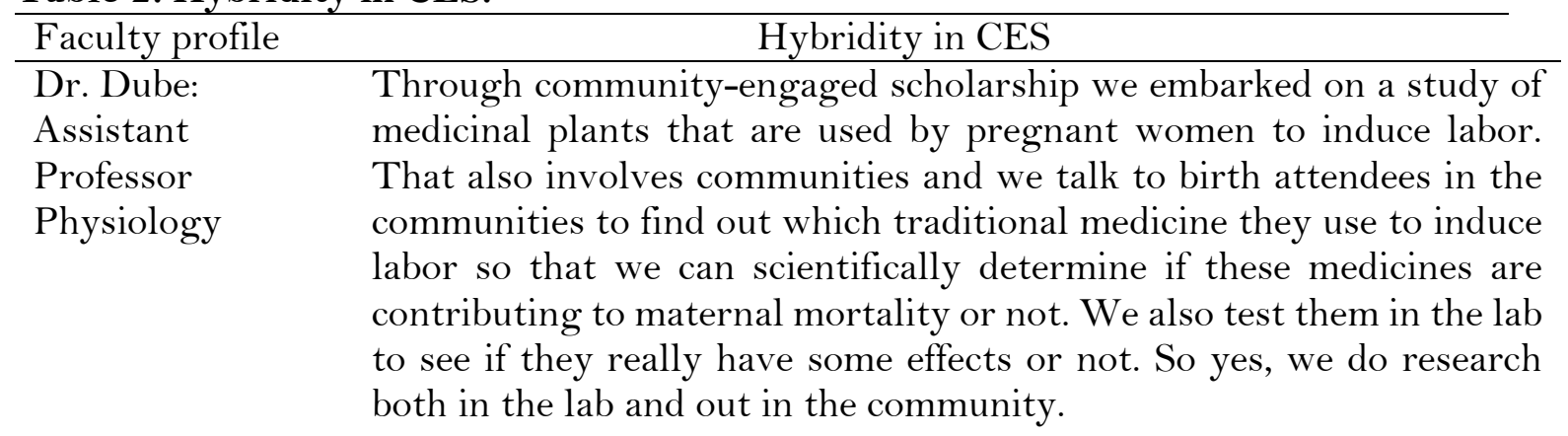

Dr. Mwala: Senior Lecturer Public Health

In Malawi, we have a very interesting pattern where the stewards of health are different from the stewards of growth and development. What I mean is that, the government ministries directing these are different...child stimulation and development and nutrition ... extension workers in the communities are different. I am involved in program integration where various fields of knowledge and expertise can be brought together to address the issues of child nutrition and malnutrition.

Dr Madzi Senior Lecturer Community engagement involves putting together different kinds of knowledge via what is called community diagnosis. This is where we Public Health integrate the various medical knowledge we have developed and taught the medical students with knowledge from the communities. The knowledge and evidence supports communities to develop their own solutions to medical problems. Faculty members and students go out to the communities streamline solutions based on the community and ecological evidence and knowledge. We believe knowledge/or solutions to medical problems do/es not merely reside in the university but in the communities. It is when these are brought together that we are able to alleviate problems.

Dr. Nyanja:

Assistant

Community engagement entails a division of labor. I can work on Professor issues such as the development of starch and quality food and water. Chemistry $\mathrm{My}$ role then is to collaborate with other disciplines in the social sciences to do the other bit when it comes to community engagement. 


\begin{tabular}{ll}
\hline Faculty profile & \multicolumn{1}{c}{ Hybridity in CES } \\
\hline Dr. Dziko: & My community engagement is related to orthopedics. I am concerned \\
Lecturer & with the correction of deformities or functional impairments of the \\
Orthopedics & skeletal system and associated structures, such as muscles and \\
& ligaments. Community engagement in my mind links medical \\
& knowledge and local knowledge to meet people's needs. We work with \\
& the community to learn their problems and ways to deal with them. \\
& We also help them to access and use modern medical approaches to \\
& orthopedic issues.
\end{tabular}

The narratives about the backgrounds and nature of the CES work offered by Doctors Dube, Madzi, Dziko, Mwala and Nyanja created a clear picture of how the hybridization of multiple medical knowledge systems acts as a strategy to make medical education relevant for Malawi. These five faculty members' philosophical and epistemological approaches, though somehow different in their own light, were characteristically uniform in that they conjure multiple kinds of medical knowledge. This hybridization of knowledge was presented as marrying traditional medicine and modern medicine for Dr Dube, Dr Dziko and Dr Mwala, in their physiology, orthopedics, and public health based CES respectively. Similarly, Dr Nyanja's hybridity in CES was reflected in his vehement opposition to basic scientists working in isolation in the community. He was of the view that, relevant medical education and services to community was best achieved via interdisciplinary collaboration where faculty at the COM collaborate with faculty in the social sciences who are experts in community engagement in order to enable effective CES.

In addition, Dr Mwala's views on CES reflected on the hybridization of actors and stewards in child development and nutrition. He pointed out that his CES brought together actors from different government ministries. These officials are supposed to be working together but find themselves working in isolation due to poor coordination systems. Dr Mwala stated that CES enables him to bring together and unify the work of two ministries namely, the Ministry of Health and that of the Ministry of Education towards working for issues of child development. Dr Madzi's focus was on the contextualization of biomedicine via "community diagnosis... where students integrate various knowledge they have learned in the community." It is clear that faculty members were creative and used diverse ways to engage with the public. Furthermore, all these perspectives reveal that there was no one simple form of CES.

Like the other four faculty members, Dr Dube indicated that CES involves solving big society problems by co-creating medical knowledge with communities. This enabled them as scholars and professionals in the medical education to advance their careers and contribute to making the medical field relevant to Malawian needs. This was done, as noted by Dr Dube, by bridging modern and traditional medicine through working with various community groups like women and traditional doctors "to see if the medicines they use have the claimed properties". The faculty members' responses explicitly mentioned the need to link various epistemologies as a strategy to improving their teaching, research and service provision. Insights from the postcolonial theory show that, the faculty profiles and their narratives expose the paradox of how African faculty themselves are caught up in the very processes, which they seek to resist, such as the dependency on Western medical knowledge as the only true way to practice medicine. The evidence for this is reflected in the faculty's outline that 
their motivation for conducting CES was to find the scientific backing of the medical properties in traditional medicine as examples of quotes showed in table two. If the objective is to bring African traditional ways of healing to the same level as their Western counterparts, one is inclined to ask why there was need to validate it though a laboratory based research. The form of hybridization of scientific and traditional medical knowledge tended to suggest a denial of coevalness as expressed by Bhabha, (1985). This however, demonstrates the complexities evident in CES shown in the way the SSA faculty members have to satisfy multiple audiences.

The reality that faculty conduct CES for career and professional motivations means that they have to engage in CES in accordance with international research standards with the results of CES being published in international journals to gain promotion and recognition. This might explain why the plans, products and strategies for such knowledge are basically in English as opposed to local languages. Yet, even if they were to communicate this knowledge in local language, the idea of hybridities and multiple languages makes it even more complex. Put succinctly, the fact that Malawi has thirteen ethnic languages, which in turn have numerous dialects (Kayambazinthu 2004) means that the faculty would be faced with a challenge to translate their ideas into the different indigenous languages and dialects should they employ vernacular languages in their works. According to Forester (2007) we can use profiles in research to explore the challenges and opportunities that practitioners face in their fields. Like other narrative and ethnographic material, profiles provide phenomenologically rich qualitative data that can be corroborated by existing literature from our fields. Sensitively analyzed profiles facilitate theory-building because these practice stories can help us clarify theoretical problems on the topic under study. ${ }^{6}$ The next section dwells on the theme of resistance in CES.

\section{Resistance in CES}

Concepts from the postcolonial theory helped in the determination of the complications in CES. The concatenation of the scientific and traditional, interdisciplinary collaboration and unification of actors in medicinal knowledge were cast as aspirations or motivations and common conceptual frameworks that faculty used in their CES in a quest to bring to reality the postcolonial mandate of Africanizing medical knowledge. The faculty profiles demonstrate the complicated bifurcations of knowledge, disciplines and actors in the field of medical education, and the complexities that faculty members face while doing CES. Faculty spoke about real resistance from community members in the form of refusal to reveal their knowledge. Faculty also noted the difficulty arising from working in silos and how they tried to avoid that by emphasizing interdisciplinary approach to CES. They also pointed out the importance of collaborative efforts, and the sharing of knowledge and resources for various actors in government who deal with health related issues. Most importantly, faculty thought that CES ought to expose students to these complexities in order to create a portfolio of medical knowledge that offers relevant and Malawian context specific medical training. The complexity of doing interdisciplinary work via CES may have several explanations. For instance, local and international funding mechanisms offer more funding to basic sciences as opposed to the humanities. Second, the institutional organization and culture that separates faculty groups into departments according to disciplines makes it rather hard to make collaboration possible. This means that while faculty aspire for hybridity through interdisciplinary collaborations, the practice is usually overwhelming and hard to do because

${ }^{6}$ For details on use of profiles, see: http:// courses2.cit.cornell.edu/fit117/UP.htm 
faculty members strive to outdo each other's CES projects in order to secure competitive and scarce funding.

The cross-cutting finding from the faculty profiles and how they relate with the confluence of the fields of higher education and medicine, was a reflection of Michel Foucault' post-colonial view of knowledge production and power which states that each society has its own regimes of knowledge that it accepts as truth. The faculty members at the COM never took it for granted that medical knowledge practice at the university is a scientific system that is supposed to be universally accepted by all who operate in the field. As a result, the traditional medical knowledge uncovered through CES needed to be authenticated and validated with laboratory research and science in order for it to coeval with Western medical knowledge. It was also noted that knowledge production and Medical education is not a simple endeavor that one can easily inherit, brush off from their colonial past, or simply cut and paste from the more powerful international universities. Hence, faculty ultimately realized that the interplay of hybridity and resistance in CES demanded their intellect, time, resources, trust, ethical integrity and professionalism.

Professionalism is a key drive for CES in medical education. The significance of professionalism in handling the complex challenges and problems faced by faculty members arises in the way it was used to deal with the postcolonial resistance encountered during the CES. Dr. Dube's and Dr. Dziko's profiles raised issues of resistance in their outline of the encounters of the community refusals to share knowledge. In their view, CES should be driven by "trust and truthfulness and openness to the community." In addition, Dr. Mwala's views highlighted the complexity of resistance. Faculty members face resistance both from local communities and international funding agencies, with the latter resisting local knowledge. This makes CES complex and hard in times of scarce funding. For instance, Dr. Mwala was critical of international donors' use of funds to motivate or punish governments. His solution to rejecting this outside influence was for the Malawi government, a major funder for HEI, to depend more on local taxes from people to support medical education and thus, develop local solutions to local problems.

Dr. Madzi also spoke about how students resist and question community behaviors, or question the relevance of knowledge learned in class in the development of their own knowledge through CES. This kind of resistance, while it makes teaching a challenging job, enables creativity and ingenuity that result in the generation of a Malawi context specific medical training. Dr. Nyanja also reflected resistance to an improper push at institutional level that merely calls for all disciplines to conduct CES even when their disciplines may not directly render their work viable for CES. He preferred interdisciplinary collaboration instead of the expectation of a CES for all. Resistance was a prominent issue for Dr. Dziko. Faculty realized that they had to develop strong links with the community and engage people to own their knowledge and the projects in order to make medical education and service relevant to the communities. While this strategy worked for the most part, community members have strong trust in their own ways of knowing. Faculty acknowledged that although community resistance made their work tough and complicated, they learned and discovered the real issues affecting communities and developed powerful ways to deal with problems. In the final analysis, faculty perspectives on CES revealed that it was between the hybridization and resistance of CES that real academic work and scholarship and service was performed, albeit in multiple and complicated ways as narratives in the table that follow demonstrate.

\section{Discussion}


The review and analysis of the faculty profiles from a postcolonial approach revealed that community engagement work is manifold, difficult and complex. A consideration of this work from a postcolonial lens of hybridity and resistance allowed us to see the limitations of conceptualizing dualities and binary oppositions instead of intricacies and the challenges that result in the punitive division of knowledge. Faculty profiles also revealed the nature of the Malawian faculty's endeavors to contextualize CES and knowledge production amidst numerous challenges.

Table 3. Resistance in CES.

Faculty

Dr. Dube:

Assistant Professor

Physiology

Dr. Mwala:

Senior Lecturer

Public Health

Dr Madzi

Senior Lecturer

Public Health

Dr. Nyanja:

Assistant

Professor

Chemistry

Dr. Dziko:

Lecturer

Orthopedics
Resistance in CES

...barriers come, especially when you are dealing with traditional

healers. They think that if they tell you about the herbs they use one will use them to get money. There is a lot of mistrust. Of course, to them it's justified because there have been people before who got their knowledge and never came back, especially researchers who come from outside the country. The researchers would get the healers' knowledge about traditional medicine, go and patent those plants and leave the source of the knowledge without any possible benefits from their expertise.

Normally it's like you have to apply for funding grants from outside. Depending on the questions I ask, funders influence those questions and the type of knowledge that we produce. The question then becomes, how relevant is the knowledge we produce to our local communities?

Community engagement enables application and creativity for students. They ask critical questions after spending time in the community hospital applying what they would have learned. Some question why communities behave in the way they do. They also ask why they have to treat a particular disease in given way and in another.

You are forcing me now to go to the community when I am a natural scientist. Why should I engage with the community? This depends on the project. There will be particular projects in which community engagement is a must. There are projects in our faculty that do not even require community engagement because they are basic things that merely deal with the theoretical, but now you are forcing me to find reasons why I should engage with the community.

The challenge we face when engaging with communities is that sometimes people do not trust the medical help we offer them. Some people have their own ideas of what causes conditions such as body disabilities. They may not understand for example, what causes polio. So they may believe that witchcraft or bad luck cause body deformity. Rather than seek help from the hospital, they trust their traditional ways of healing more. 
A clear picture of the epistemological struggle between the local and international and the modern and traditional, and basic sciences and social science disciplinary perspectives in medical knowledge, was cast in sharper contrast with a desire to unify and legitimatize various African knowledge with modern science to solve health problems via CES. This was done by testing traditional medicine using modern laboratory equipment to find, as Professor Dube put it, the "scientific backing for the medicines". Therefore, faculty members exposed what they thought was their role in community development and their contribution to the health of the nation.

Moreover, faculty members used CES as a strategy to achieve their role of public intellectuals who hold the fluid and hybrid positions of the subject, critic and expert of social and medical life (Hale, 2008; Isaacman, 2003; Boyer, 1996; Harstock, 1983). Faculty members exercised self-moderation and self-critique by, for example, problematizing the cultural practice that uses untested medical herbs to induce labor. They were also self-critical after realizing that they fail to contribute to the needs of community by hiding the knowledge away from the community. This was reflected in the statement Professor Dube made that: "There are simple things that we know which, if they knew, would tremendously change their (community members') lives."

The role of faculty members as experts took up the task of testing knowledge and legitimizing it with other forms of medical knowledge. The results from the studies are published and the products of the CES are sold or provided for profitable gains. While faculty members understand the community members' resistance and agency in commoditizing their traditional knowledge, they counter that resistance by doing it anyways. But, how might faculty members drive their own resistance to commercialization of knowledge through community-engaged research? This scenario highlighted the complexity of the role of faculty as public intellectuals. While faculty members are usually cast as complicit in legitimizing oppressive new foreign cultures, such as modern medicine, the faculty profiles showed that one aspect of their role, which they recognized, was to empower and preserve the knowledge that otherwise has been considered as primitive and dangerous.

While some scholars would voice concern that faculty members' practice of such CES waters down and reduces scholarship to market responsiveness and creating entrepreneurial universities (Singh, 2001), faculty members tend to see beyond the market and do not see themselves as victims of the market forces (Nkhoma, 2014). These faculty members' profiles show motivation to explore the significance of representing and engaging all forms of medical knowledge at a global, national, and communal level to show the power of the African university rather than merely positioning local medical knowledge as a source of revenue or patents. They additionally rejected the positioning of African universities and communities as sites of Western medical deficiencies, or as empty bottles to be filled with Euro-American medical knowledge.

Faculty members, it would appear, have paid serious attention to the criticism that scholars of African higher education, such as (Mamdani, 2008b; Zeleza, 1997), have long articulated that African communities should not be treated as "a tropical laboratory [that can be used] to test and refine the methodological and theoretical frameworks of the disciplines" (Zeleza, 1997:195). The pervasive criticism of African faculty members as producers of knowledge that is only useful in furthering their careers and simply refining existing (and Eurocentric) theories and medical knowledge with no utility to the communities where the knowledge is drawn from could apply to faculty members' profiles. Calhoun (1998:21), in an analysis of higher education as a public good, asks, "Whose public? Whose good?" we refer to in our discussion of knowledge production. He warns that, “ $[\mathrm{P}]$ ositing a community as 
the basis of the public good is apt to obscure contests over collective identity and disempower those whose projects are not in accord with those of dominant groups" (Calhoun 1998:22).

We also discovered, from the faculty profiles, the challenges and negative impacts of dealing with communities especially in an attempt to legitimize their ways of knowing. This is in line with the insight that (Kamola, 2010: 163) has emphasized that:

The production of academic knowledge has serious political stakes, themselves structured by the political and material institutions of the university. This argument becomes increasingly important as, around the world, spaces of academic teaching and research become ever more subsumed within a highly asymmetrical 'global market place'. As such, it becomes even more necessary to 'force open' alternative forum, practices and standards of 'excellence' by publicly promoting a vision of the university as a site engaged in pursuing the values, desires, imaginations and demands of greater social redistribution.

The faculty profiles remind us, as Kamola (2010) shows that, a university and people it serves do not exist in a vacuum. Conducting CES requires the building of mutual trust, an establishment of the benefits of such work and winning support from various stakeholders. The profiles showed that as faculty members deal with the community, they must realize that community members also have their own motivations and expectations which may at times appear as obstacles to scholarship. Much as this conditionality may act as an obstacle, the success of engaged faculty members depends on their integrity rather than craftiness, truthfulness or tact.

The above-noted understanding influences two strategies that can enhance CES and relevant knowledge production in SSA. First, resistance can be as a vital component of CES, even though the engaged parties have quite differing views and perspectives regarding knowledge production and reasons for resistance. For African faculty members, CES is a platform for performing resistance in the form of speaking truth to the powerful colonial ways of knowing and what is considered legitimate knowledge. For the locals outside the confines of the university, resistance is a creative approach that enables the holding of a conversation to communicate and protect what is rightfully their knowledge. Therefore, relevant CES, rather than coopting and silencing community perspectives and rejecting what is erroneously thought of as the disinterested "other", should endeavor to identify and build links and thus resistance becomes a creative and productive practice that is mutually beneficial for all involved in knowledge production via CES.

Second, African universities have tended to work towards creating a common core of approaches to CES (Preece, Ntseane, \& MmaB, 2012). University mission statements, as noted at the COM, emphasize teaching, research, service and consultancy that applies to the local context - a differentiated understanding of CES. This contextualized understanding of CES has resulted in faculty rejecting the one- size- fits- all approach to CES. The reality is that CES ought not to be the same across all types of higher education institutions. Moreover, not all disciplines and departments might be better positioned to undertake CES in the same way. A differentiated and pluralistic approach to CES that emphasizes collaboration across actors, disciplines, and departments might be the best way to enhance CES practice. If we seriously consider hybridity in CES and knowledge production, we find that knowledge boundaries are superficial, and both scientific and traditional approaches to curing ailments/ addressing health related problems prove to have some remarkable inadequacies. Moreover, 
what faculty in Malawi demonstrated is that the process of bringing together various actors and their ways of knowing in CES does not simply have one hybridized CES but multiple ones. Bhabha (1994) helps us to note that such divisions and the multiple hybrids that ensue are always ambivalent. An important strategy, therefore, for enhancing CES demands that we take seriously insights from Loomba (2015). Instead of pitting the old, traditional, local and indigenous against the scientific, modern and international, it is more useful that CES projects in knowledge production "trace how each set of terms and approach is evoked, by whom, and to what end. What each evocation makes visible. What do they occlude?" (179). It is after realizing this that we can discover and contribute to the meaningful development of relevant knowledge and higher education for the SSA.

\section{Conclusion}

This paper was situated in the discourse of CES for knowledge production to attain relevant African higher education. The critical issues surrounding the debate on the relevance of African higher education are that we have African universities as just universities located in Africa. There is a strong indication that universities in the SSA ignore their potential areas of strength because they are too focused on imitating successful Anglo or American institutions (Preece, Ntseane, \& MmaB, 2012; Wendland, 2012; Wendland, 2010; Sawyer, 2004). However, evidence from this paper suggests otherwise. Faculty members in Malawi, especially those at the selected medical school, appear to take up the postcolonial appeal that universities must derive their inspiration from the context in which they find themselves and reflect the challenges they face in their immediate society. I have thus argued that the practice that underlies CES in medical education is far more institutionally, and culturally specific. As a result, it was not merely copied from one context to the next.

Chapman \& Austin (2002) postulate that HEIs in countries in transition face challenges that are peculiar to their context of existence, and in the same vein, possible solutions that could be deemed appropriate/effective for the unique challenges the particular institution would be grappling with are likely to vary from one institution to another. Thus, the paper has demonstrated how Malawian faculty members use CES to bridge various perspectives in medical knowledge to attain, in a postcolonial sense, relevant African knowledge. With insights from Bhabha (1994) on hybridity and resistance, CES practice in the Malawian higher education sector can be characterized as a pluralization of medical knowledge, itself engulfed in constant resistance to reshape faculty members themselves, the knowledge, and the practices they use to meet the unique needs of their communities. The ideal of multiple CES hybrids suggests that CES and the relevant medical knowledge will undoubtedly continue to be negotiated and rearticulated. The principal caution with promoting CES is allowing it to become a fixed, stable strategy or descriptor of scholarship in SSA, rather than to refer to it as a field or space of productive play between and among various forms of knowledge and actors. While lessons drawn here may be context-specific, other African scholars and scholars in American and European higher education can learn from the way Malawian faculty members use CES as a strategy to make their work relevant to their context.

\section{References}

Altbach, P. G. (2013). Advancing the national and global knowledge economy: the role of research universities in developing countries. Studies in Higher Education, 38(3), $316-$ 330. 
Appiah, K. A. (1991). Is the post-in postmodernism the post-in postcolonial? Critical Inquiry, $17(2), 336-357$.

Atkinson, R. (Ed.). (1998). The life story interview. London: Sage.

Bhabha, H. K. (1985). Signs taken for wonders: Questions of ambivalence and authority under a tree outside Delhi, May 1817. Critical Inquiry, 12(1), 144-165.

Bhabha, H.K. (1994). 'Remembering Fanon: Self, Psyche and the Colonial Condition',in P. Williams and L. Chrisman (eds), Colonial Discourse and Postcolonial Theory. New York: Columbia University Press, pp. 112-123.

Bloom, D., Canning, D \& Chan, K. (2006). Higher Education and economic development in Africa. Washingston DC. World Bank.

Broadhead, R.L,\& Muula A.S.(2002). Creating a medical school for Malawi: problems and achievements. BMJ.; 325:384-7. doi: 10.1136/bmj.325.7360.384.

Burawoy, M. (2010). Public sociology in the age of Obama. In H.E. Fitzgerald, C. Burack, \& S.D, Seifer (Eds.) Handbook of Engaged Scholarship: Contemporary landscapes, future directions (pp. 149-160). Vol 2. East Lansing: Michigan State University Press.

Calhoun, C., (1998). 'The Public Good as a Social and Cultural Project', in Powell, W. W. and Clemens, C.C., eds., Private Action and the Public Good, New Haven, CT: Yale University Press.

Castells, M. (2010). End of Millennium: The Information Age: Economy, Society, and Culture (Vol. 3). John Wiley \& Sons.

Chapman, D. W., \& Austin, A. E. (Eds.). (2002). Higher education in the developing world: Changing contexts and institutional responses. Westport, CT: Greenwood Publishing Group.

Clark, B. (1998). Creating Entrepreneurial Universities: Organizational Pathways of Transformation. Higher Education. Oxford: Pergamon-IAU Press.

College of Medicine (2010). College Student Prospectus for 2010. University of Malawi Press: Blantyre

Dahlenburg, G.W. (1993). Letter from Malawi: the first year of the College of Medicine of the University of Malawi. PubMed. Trop Doct. 23:4-6.

Dempsey, S. E. (2010). Critiquing community engagement. Management Communication Quarterly, 24(3), 359-390.

Eisemon, T. O., \& Balkom, W. D. V. (1988). Universities and the Development of Scientific capacity in African Countries: a critique. Compare, 18(2), 105-116.

Foucault, M. (1983). Discourse and truth: The problematization of parrhesia. Berkeley: University of California.

Furco, A. (2010). The engaged campus: Toward a comprehensive approach to public engagement. British Journal of Educational Studies, 58(4), 375-390.

Hale, C. R. (Ed.). (2008). Engaging contradictions: Theory, politics, and methods of activist scholarship. Berkeley, Los Angeles: University of California Press.

Harries, A. D., Kumwenda, J., Zijlstra, E. E., Broadhead, R. L., Squire, S. B., \& Salaniponi, F. M. (2003). Teaching tuberculosis control to medical undergraduates: the Malawi experience. The international journal of tuberculosis and lung disease, 7(9), 842-847.

Holland, D. G. (2009). Between the practical and the academic, the relation of mode 1 and mode 2 knowledge production in a developing country. Science, Technology \& Human Values, 34(5), 551-572.

Isaacman, A. (2003). Legacies of engagement: Scholarship informed by political commitment. African Studies Review, 46(1), 1-41. 
Kamola, I. A. (2010). Producing the global imaginary: Academic knowledge, globalization and the making of the world. Minneapolis: University of Minnesota.

Kayambazinthu, E. (2004). The Language Planning Situation in Malawi. In R.B Baldauf \& R.B. Kaplan (Eds.). Language Planning and Policy: Africa (vol. 1) -Botswana, Malawi, Mozambique and South Africa (pp 79 - 149). Clevedon: Multilingual matters.

Lazarus, J., Erasmus, M., Hendricks, D., Nduna, J., \& Slamat, J. (2008). Embedding community engagement in South African higher education. Education, Citizenship and Social Justice, 3(1), 57-83.

Loomba, A. (2015). Colonialism/postcolonialism. London and New York: Routledge.

Lwanda, J. (2002). Doctoring the brain drain: Medical case of Malawi. African Issues, 30(1), 47-51.

Mamdani, M. (2008a). Scholars in the marketplace: The dilemmas of neo-liberal reform at Makerere University, 1989-2005. African Books Collective.

Mamdani, M. (2008b). Higher education, the state and the marketplace. JHEA/RESA, 6(1), $1-10$.

Matthew, S. (2010). Teaching and researching Africa in an 'Engaged'way: the possibilities and limitations of community engagement. JHEA/RESA, 1, 1-21.

Mkandawire, A. C. (1998). Living my destiny: a medical and historical narrative. Limbe, Malawi: Popular Publications.

Nkhoma, N. M. (2014). Under the invisible hand? Market influences on community engaged scholarship in Malawian higher education. Reconsidering Development, 3(1), $1-15$.

O’Meara, K., (2008). Motivation for faculty community engagement: Learning from exemplars. Journal of Higher Education Outreach and Engagement, 12(1): 9-24.

Obamba, M. O. (2013). Transnational knowledge partnerships: new calculus and politics in Africa's development. Compare: A Journal of Comparative and International Education, $43(1), 124-145$.

Personal Narrative Group (1989). Interpreting Women's Lives: Feminist Theory and Personal Narratives. Bloomington, IN: Indiana University Press.

Pigg, S. L. (1995). Acronyms and effacement: traditional medical practitioners (TMP) in international health development. Social Science E Medicine, 41(1), 47-68.

Preece, J. (2013). Towards an Africanisation of community engagement and service learning. Perspectives in Education, $31(2), 114-122$.

Preece, J., Ntseane P.G., Modise, O.M. and Osborne, M. (2012) (eds). Community engagement in African Universities: perspectives, prospects and challenges. London: NIACE.

Riessman, C.K. (2008). Narrative methods for the human sciences. Los Angeles: SAGE.

Samoff, J. (1999). Education sector analysis in Africa: limited national control and even less national ownership. International Journal of Educational Development, 19(4), 249-272.

Sawyer, A. (2004). Challenges facing African universities: Selected issues. Accra: Association of African Universities.

Singh, M. (2001). Enabling transnational learning communities: Policies, pedagogies and politics of educational power. In Internationalizing higher education (pp. 9-36). Springer Netherlands.

Spivak, G. C., \& Harasym, S. (1990). The post-colonial critic: Interviews, strategies, dialogues. Psychology Press.

Teferra, D., \& Altbach, P. G. (2004). African higher education: Challenges for the 21 st century. Higher Education, 47(1), 21-50. 
Thomas, L. M. (1998). Imperial concerns and 'women's affairs': State efforts to regulate clitoridectomy and eradicate abortion in Meru, Kenya, c. 1910-1950. The Journal of African History, 39(01), 121-145.

Waghid, Y. (2002). Knowledge production and higher education transformation in South Africa: Towards reflexivity in university teaching, research and community service. Higher Education, 43(4), 457-488.

Wendland, C. L. (2010). A Heart for the Work: journeys through an African medical school. Chicago: University of Chicago Press.

Wendland, C. L. (2012). Moral maps and medical imaginaries: clinical tourism at Malawi's college of medicine. American Anthropologist, 114(1), 108-122.

World Bank (2007). The Knowledge Economy. Washington DC: The World Bank.

World Bank. (2009). Accelerating Catch-up: Tertiary education for growth in sub-Saharan Africa. Washington DC: The World Bank.

Zeelen, J., \& van der Linden, J. (2009). Capacity building in Southern Africa: experiences and reflections: towards joint knowledge production and social change in international development cooperation. Compare, 39(5), 615-628.

Zeleza, P. T. (2002). "The Politics of Historical and Social Science Research in Africa. Journal of Southern African Studies, 28 (1): 9-23.

Zeleza, P.T., (1997). The Perpetual Solitudes and Crises of African Studies in the United States. Africa Today, 44 (2): 193-210.

\section{Acknowledgements}

This research was supported by the Interdisciplinary Center for the Study of Global Change (ICGC) Compton Fellowship, University of Minnesota and University of Western Cape, Institute for Post School Studies (IPSS) with support from the Carnegie Cooperation of New York. Special thanks should also go to Andrew Furco and David Chapman for providing very important feedback. The staff and faculty at the COM in Malawi also deserve appreciation. The author would also like to thank the anonymous reviewers for their feedback and comments.

\section{About the Author \\ Nelson Masanche Nkhoma is a Research Fellow in the Institute for Post School Studies at the University of the Western Cape (UWC). His teaching, service and research focuses on African higher education, the role of universities in national development and faculty community-engaged scholarship in the global knowledge economy. As a practitioner, he has work at the nexus of education, and development. He has been part of several higher education projects including the five years MasterCard Learn, Earn and Save Initiative in East Africa in partnership with the University of Minnesota to assess the impact of entrepreneurship education on economically marginalized youth in Kenya, Tanzania and Uganda, as well as the National Research Fund (NRF) supported research project on access to higher education: aspirations, choices and opportunities in South Africa. He is currently involved in a Mapping Higher Education Policy in Africa (MHEPA) project.}

